\title{
Morfologia externa dos imaturos de Caligo teucer (Linnaeus) (Lepidoptera, Nymphalidae) ${ }^{1}$
}

\author{
Neuda A. de Souza ${ }^{2}$; Antônio F. de S. L. Veiga ${ }^{3}$; Mirna M. Casagrande ${ }^{4}$; Manoel G. C. Gondim Jr ${ }^{5}$ \\ ${ }^{1}$ Contribuição número 1665 do Departamento de Zoologia, Universidade Federal do Paraná. \\ ${ }^{2}$ Rua Jacaúna 243, Iputinga, 50670-160 Recife, Pernambuco, Brasil. E-mail: jabing@terra.com.br \\ ${ }^{3}$ Laboratório de Zoologia, Departamento de Biologia, Área de Zoologia, Universidade Federal Rural de Pernambuco. \\ Rua Dom Manoel de Medeiros, 52171-900 Recife, Pernambuco, Brasil. E-mail: afsouzaleão@click21.com.br \\ ${ }^{4}$ Departamento de Zoologia, Universidade Federal do Paraná. Caixa Postal 19020, 81531-980 Curitiba, Paraná, Brasil. \\ E-mail: mibras@ufpr.br \\ ${ }^{5}$ Laboratório de Acarologia, Departamento de Agronomia, Área de Fitossanidade, Universidade Federal Rural de \\ Pernambuco. Rua Dom Manoel de Medeiros, 52171-900 Recife, Pernambuco, Brasil. E-mail: mguedes@ufrpe.br
}

\begin{abstract}
External morphology of the immatures of Caligo teucer (Linnaeus) (Lepidoptera, Nymphalidae). This paper describes the immatures of Caligo teucer teucer (Linnaeus,1758), from material reared in northeast Brazil. The larva feed on leaves of Musa spp. (Musaceae), Heliconia bihai (Heliconiaceae), Canna indica (Cannaceae) and Alpinia purpurata (Zingiberaceae).

KEY WORDS. Brassolinae; host plant; Neotropical.
\end{abstract}

RESUMO. Este trabalho descreve os imaturos de Caligo teucer (Linnaeus, 1758). O material criado é proveniente do nordeste do Brasil. As larvas se alimentam de folhas de bananeira Musa spp.(Musaceae), Heliconia bihai (Heliconiaceae), Canna indica (Cannaceae) e Alpinia purpurata (Zingiberaceae).

PALAVRAS-CHAVE. Brassolinae; Neotropical; planta hospedeira.

A família Nymphalidae compreende cerca de 2000 espécies na região Neotropical, das quais 788 espécies ocorrem no Brasil. Em Pernambuco foram registradas 139 espécies, com apenas nove representantes de Brassolinae (BROWN JR \& FreITAS 1999).

De acordo com Casagrande (2002), os Brassolinae Boisduval, 1836 são exclusivamente Neotropicais, sendo seu limite ao sul o Norte da Argentina, Paraguai e Bolívia e que a monofilia da subfamília está baseada no uso de monocotiledôneas como plantas hospedeiras das larvas, pela presença de célula e veia umerais, células discais fechadas em ambas as asas e pela presença de androcônias e pincéis de pêlos nas asas.

As espécies do gênero Caligo Hübner, 1819 são de grande porte, sendo que nenhuma delas possui menos que $100 \mathrm{~mm}$ de envergadura; as Iarvas apresentam coloração parda no último estádio, são gregárias nos três primeiros estádios e na sua grande maioria com hábitos crepusculares (Penz et al. 1999, Casagrande \& Mielke 2000a).

Segundo García-Barros (1987), García-Barros \& Martín (1991), Freitas \& Oliveira (1992) e García-Barros, (1999) dados morfológicos dos imaturos têm sido aplicados com sucesso nos estudos de sistemática de Lepidoptera e têm demonstrado serem úteis e eficientes para esclarecer a relação entre as subfamílias de Nymphalidae.
Segundo Blandin \& Descimon (1975), Caligo teucer (Linnaeus, 1758) é largamente distribuída na Bolívia, classificando-a como pertencente ao grupo II, espécies "amazoniennes" e Ramos (2000), constatou a ocorrência de C. teucer em levantamento realizado no Brasil na região amazônica. Também para o gênero são reportadas para Pernambuco SiLva et al. (1968), as espécies: Caligo brasiliensis brasiliensis (Felder, 1862) e Caligo illioneus praxsiodus Fruhstorfer, 1912, este certamente um erro de identificação. Este trabalho teve como objetivo estudar a morfologia externa de larvas de $\mathrm{C}$. teucer e levantar as diferentes plantas alimentícias utilizadas. O material é proveniente dos municípios de Pombos (Agreste) e Recife no Estado de Pernambuco.

\section{MATERIAL E MÉTODOS}

Os espécimes utilizados foram coletados de fevereiro de 2003 à abril de 2004 no Município de Pombos (Agreste de Pernambuco) em folhas de bananeira, Musa sp. (Musaceae) e no Campus da Universidade Federal Rural de Pernambuco, em Recife, em folhas de Heliconia bihai (Heliconiaceae), Canna indica (Cannaceae) e Alpinia purpurata (Zingiberaceae). Ovos, Iarvas e pupas foram mantidos na planta hospedeira até a emergência dos adultos. Exemplares de cada fase do desenvolvimento 
foram fixados em Kahle-Dietrich e posteriormente transferidos para álcool 70\%. Os exemplares estudados encontram-se depositados na "Coleção de Formas Imaturas de Insetos do Laboratório de Entomologia (LABOENTO)", Universidade Federal Rural de Pernambuco.

As observações relativas à morfologia basearam-se em materiais vivo e preservado, utilizando-se um estereomicroscópio binocular Olympus, equipado com câmara fotográfica e câmara clara.

A nomenclatura relacionada às áreas do corpo da larva está baseada em Peterson (1962) e da pupa em CASAgrande (1979). A quetotaxia das larvas segue Hinton (1946), Peterson (1962) e Stehr (1987). A nomenclatura referente à cerda filiforme seguiu a orientação de HARVEY (1991), para a família Nymphalidae.

\section{RESULTADOS E DISCUSSÃO}

Registra-se a ocorrência de C. teucer para o Estado de Pernambuco, cujas larvas al imentam-se de folhas de M usa sp. e plantas ornamentais como $\mathrm{H}$. bihai, C. indica e A. purpurata, ampliando desta forma a relação de plantas hospedeiras até então conhecidas.

\section{Ovo (Fig. 1)}

Forma arredondada, achatado no polo superior e pouco mais no inferior, com 1,8 a 2,0 mm de diâmetro por 1,7 a 2,0 $\mathrm{mm}$ de altura. Coloração branca, quando da oviposição, passando a branco leitoso, e posteriormente forma uma banda pontuada de vermel ho-carmin. Próximo à eclosão mostra cório semitransparente, possibilitando observar a coloração da cabeça e faixas longitudinais vermel ho-carmin da larva.

À semelhança das demais espécies do gênero, C. teucer apresenta o cório com ranhuras ventro-dorsais que variaram de 28 a 30, interligadas por tênues e irregulares estrias tranversais, formando entre si pequenas placas retangulares. $\mathrm{O}$ número de ranhuras é variável e se aproximam das descritas por CASAgRAnde (1979) para Caligo beltrao (Illiger, 1801), que mencionou aproximadamente 31, e MALO \& WILLIS (1961) referem-se a 26-27 ranhuras para Caligo eurilochus (Cramer, 1775).

\section{LARVA DE PRIMEIRO ESTÁDIO}

\section{Cabeça (Fig. 2)}

Sem escolos, arredondada, quase ovalar, com saliências e depressões, de coloração castanha, apresentando inúmeras cerdas escuras. Fronto-clípeo de textura lisa com mancha branca no terço superior, castanho-escuro no centro e castanho-claro no terço inferior. Mandíbulas com a mesma cor da cabeça, mais escuras apenas no bordo cortante. Conjunto de seis estemas de cor escura, sendo visual izadas frontal mente apenas quatro eformando um arco procurvo (Fig. 6), o quinto, localiza-se pouco acima da base das antenas e o sexto acima do quinto e atrás do quarto.

\section{Tórax e abdome (Figs 3-5)}

Corpo de forma cilíndrica, inicialmente com segmentos não distintos já que os limites se apresentam como rugas trans- versais e com algumas cerdas branco-leitosas, pouco amareladas. Ventralmente de aspecto transparente. Do primeiro segmento torácico partem quatro faixas vermelho-carmin, mais largas neste segmento, em direção à placa suranal, duas a cada lado do corpo (Fig. 3). Placa pronotal dividida, espiráculos arredondados com exceção do primeiro torácico e o último abdominal que são ovais e mais escuros. Após a primeira alimentação o tegumento adquire uma coloração verde, as faixas Iongitudinais perdem a coloração vermelho-carmin, passando a esbranquiçadas.

Na região dorsal, ao final do terceiro segmento abdominal, uma área de pontuações ferrugíneas, seguida de mancha ferrugínea no final do terceiro e metade proximal do quarto segmento, e novamente área como aquela do final do terceiro segmento no final do quarto e quinto segmentos abdominais ocupam a região mediana do dorso (Fig. 5). Ainda com outras duas áreas com pontuações ferrugíneas no segundo e sexto segmentos abdominais.

Placa suranal bífida, castanho clara com pontuações vermelhas, porção terminal escura, com dois pares de cerdas: o primeiro localizado pouco antes da metade das projeções da placa e a segunda na parte apical dessas (Fig. 4).

Entre as pernas protorácicas observou-se uma glândula eversível da mesma coloração da parte ventral do corpo. Esta glândula é citada por BouRgoGne (1951) como glândula jugular, enquanto que Peterson (1962) denomina-a de glândula eversível. Em relação a esta estrutura, GALLo et al. (2002) menciona-a a partir do terceiro instar em Caligo illioneus (Cramer, 1776), enquanto que MALo \& WilLIS (1961) para C. eurilochus e CASAGRANDE (1979) para C. beltrao no quinto instar, sem referencias aos estádios anteriores.

Ao final do primeiro estádio observa-se que o primeiro segmento torácico é de aspecto distinto dos demais, não apresenta as divisões transversais, em ânulos, como os demais, ou seja, com seis ânulos de igual tamanho em cada segmento. Os segmentos abdominais são divididos igualmente em ânulos, no entanto o primeiro é sempre mais largo.

Largura da cápsula cefálica variou entre 1,3-1,5 mm. No final do primeiro instar as larvas chegam a atingir $20 \mathrm{~mm}$ de comprimento, incluindo as projeções da placa suranal.

\section{QueTOTAXIA (Figs 9-13)}

\section{Cabeça (Figs 9-11)}

Encontrou-se dois tipos de cerdas, o primeiro grupo de cerdas grandes (Fig. 2) e o segundo de cerdas pequenas distribuídas pela fronte, clípeo, labro e mandíbulas (Figs 9-11). Adjacentes à sutura epicranial e de igual tamanho estão as duas duas cerdas adfrontais (AF1 e AF2). Na fronte a cerda F1 e um par de poros frontais Fa, conforme descrito por HinTon (1946), PETERSON (1962) e Stehr (1987). No clípeo C1 e C2 presentes (Fig. 9) e no labro são facilmente visualizados os três pares de medianas $M 1$, $M 2$, e M 3 e os três pares de cerdas laterais L1, L2 e L3, de acordo com Peterson (1962) (Fig. 10). Mandíbulas com duas cerdas de igual tamanho no canto inferior externo (Fig. 11). 

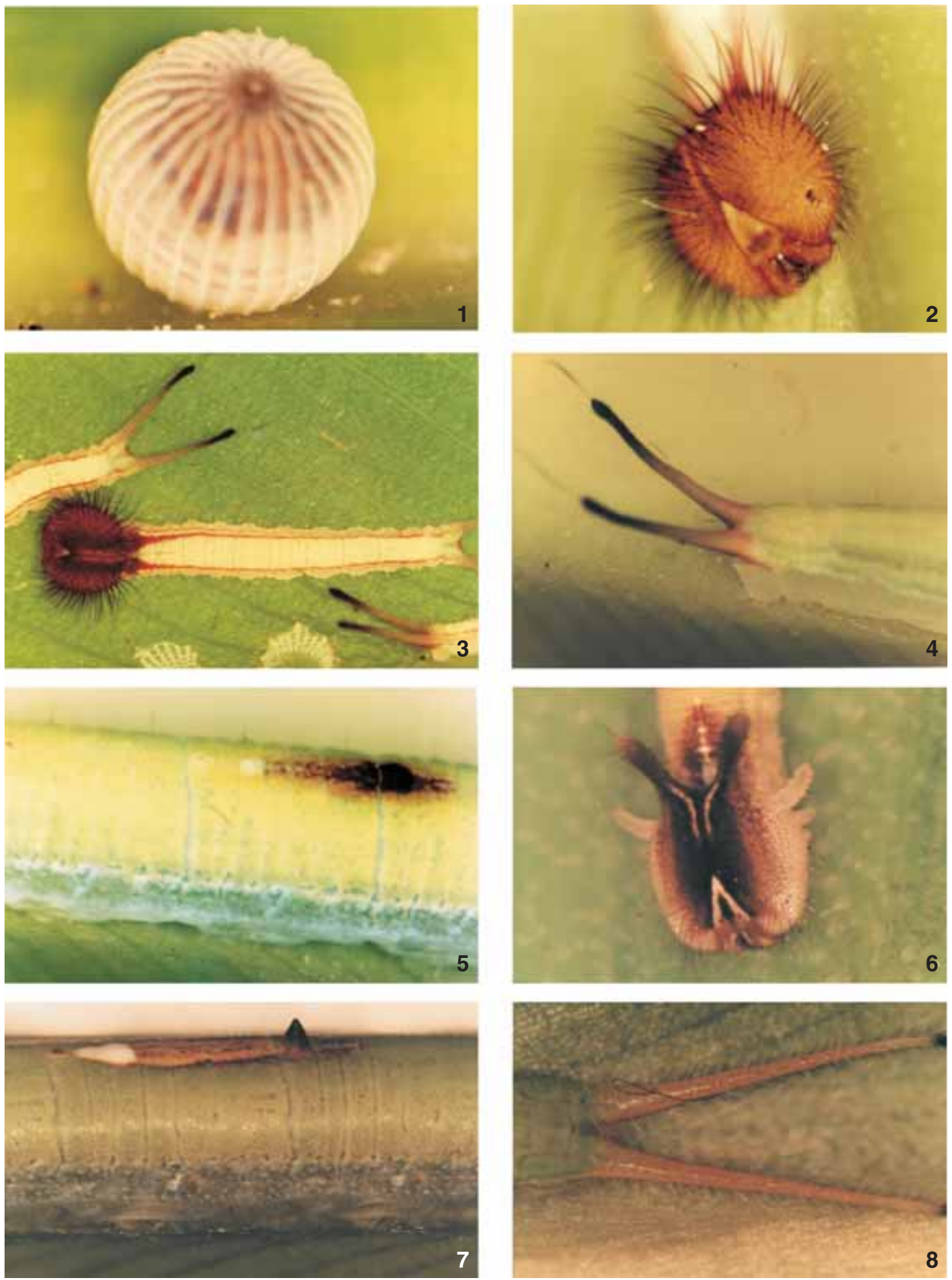

Figuras 1-8. Caligo teucer: (1) ovo no final do desenvolvimento embrionário; (2-5) larva de primeiro estádio: (2) cabeça; (3) vista dorsal de larvas recém nascidas; (4) placa suranal bífida, com dois pares de cerdas nas projeções; (5) mancha ferrugínea dorsal; (6-8) larva de segundo estádio: (6) cabeça; (7) laterais do terceiro e quarto segmentos abdominais; (8) vista dorsal das projeções da placa suranal. 


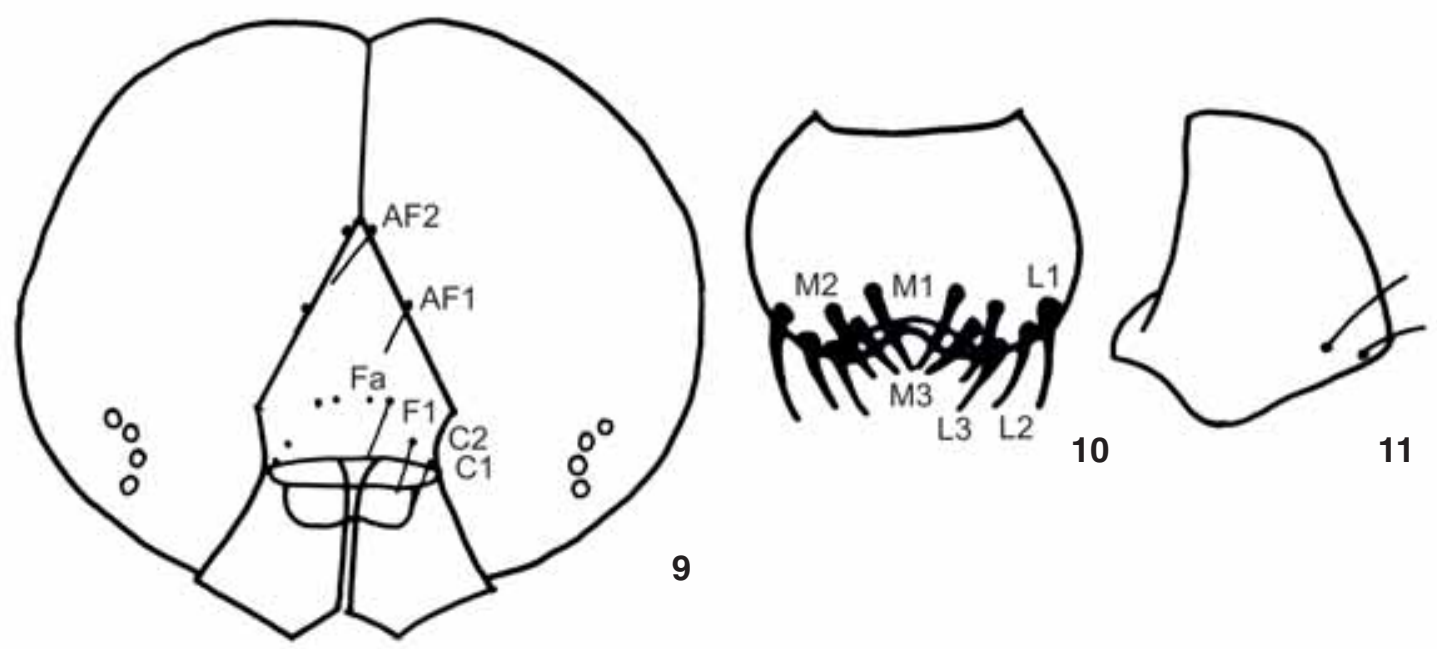

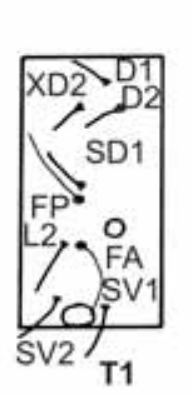

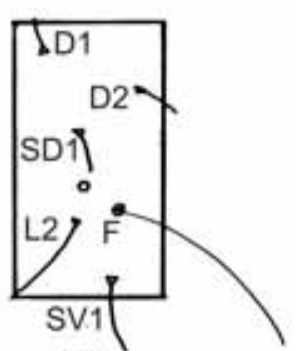

A7
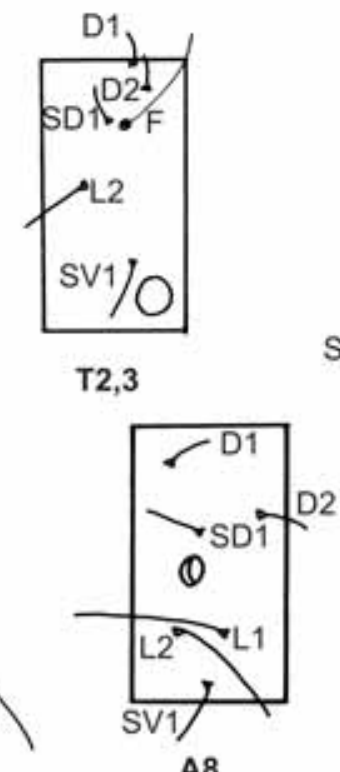

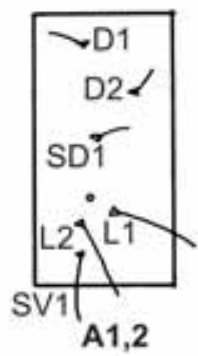

1,2

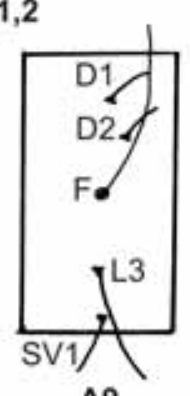

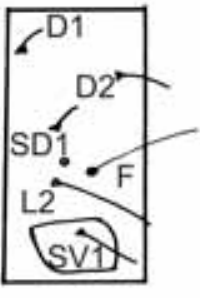

A3, $4,5,6 \quad 12$

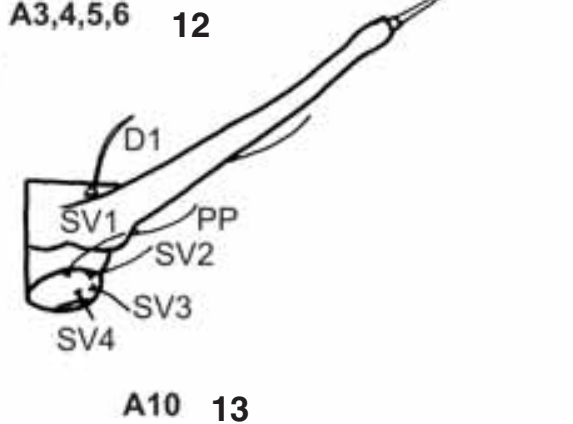

Figuras 9-13. Caligo teucer, larva de primeiro estádio. (9-11) Quetotaxia da cabeça; (9) cabeça; (10) labro; (11) mandíbula; (12-13) quetotaxia do tórax e abdome.

Tórax e abdome (Figs 12-13)

Na placa protorácica, estão presentes, a cada lado e de mesmo tamanho as cerdas anteriores XD2, D1 e D2. A inexistência da cerda XD1 difere do padrão de Lepidoptera (STEHR 1987). Antunes et al. (2003) também observaram esta ausência em Eueides isabella dianasa (Hübner, 1806) (Nymphalidae, Heliconiinae). As cerdas D1 e D2 estão presentes em todos os demais segmentos do tórax e abdome, com exceção de A10, onde D2 é ausente.

O grupo de cerdas subdorsais está representado apenas pela SD1 em quase todos os segmentos, ausente em A9 e A10, diferindo do padrão mencionado por STEHR (1987).
O grupo lateral está representado por L2 nos três segmentos torácicos. Nos abdominais L1 e L2 estão presentes em $A 1, A 2$ e A8, e em A3-A7 apenas L2 está presente, enquanto que em A9 somente L3.

O grupo subventral está representado por duas cerdas SV 1 e SV2 no protórax, e SV1 nos demais segmentos torácicos e abdominais de A1-A9. No segmento A10 estão presentes SV1, SV2, SV3 e SV4, todas na planta anal. Ainda em A10 a presença de uma cerda paraproctal PP, abaixo das projeções da placa suranal (STEHR 1987).

Observa-se também a presença da cerda filiforme nos seguintes segmentos: protórax duas cerdas, sendo uma anterior 
ao espiráculo denominada FA próxima a $\mathrm{L} 2$, e outra posterior a FP próxima a SD1. Nos segmentos que seguem, recebe a denominação de F, como no meso e metatórax em posição laterodorsal próximo a SD1, e em posição ventral e posterior ao espiráculo nos segmentos abdominais A3-A7. A última no segmento $A 9$ em posição mais dorsal que nos segmentos precedentes (HARVEY 1991).

De acordo com Harvey (1991), a cerda filiforme (F) é sensorial, sendo inclusivereceptora desons. Em GARCIA-BARROS (1989), cerdas semelhantes foram referenciadas como alongadas, finas e táteis, sensíveis a correntes de ar e classificadas como mecanoreceptoras. Estas mesmas cerdas em número e posição ocorrem em Dynastor darius darius (Fabricius, 1775), Opsiphanes cassiae (Linnaeus, 1758) e Brassolis sophorae (Linnaeus, 1758).

Ainda conforme HARVEY (1991) a presença da cerda filiforme no segmento A9 posiciona a subfamília Brassolinae em Nymphalidae, diferenciando-a das demais famílias de Papilionoidea onde é ausente.

LARVA DE SEGUNDO INSTAR

\section{Cabeça (Fig. 6)}

Com quatro pares de escolos: dorsais, látero-dorsais, laterais e látero-ventrais, diminuindo aproximadamente à metade em tamanho, em direção à região ventral. Área frontal com os dois escolos dorsais e região posterior de coloração castanho-escuro. Lateralmente, incluindo os escolos látero-dorsais, laterais e látero-ventrais a coloração é branca amarelada. $\mathrm{Na}$ parte interna dos escolos dorsais inicia-se a formação de uma faixa da mesma cor dos lados da cabeça, que desce anteriormente, acompanhando a sutura epicranial e terminando na mesma direção dos escolos látero-dorsais. Fronto-clípeo de coloração branco-amarelada com mancha central, castanho escura em forma de losangulo. Cerdas distribuídas por toda a cabeça, de cor clara nas regiões branco-amareladas e, castanho claras nas mais escuras. As mandíbulas são castanhas, quase pretas no bordo cortante (Fig. 6).

\section{Tórax e abdome (Figs 7-8)}

Tegumento do corpo de coloração verde, com pequenas manchas verde-claras encimadas por cerdas sobre calaza branco-leitosa distribuídas por todo o corpo. Faixas longitudinais permanecem visíveis. Áreas ventral,supra e subespiracular verde-clara. Pequenas projeções tegumentares sobre aqueles pontos ferrugineos que aparecem no primeiro instar com base avermelhada e ápice preto. As projeções do quarto e quinto segmentos abdominais de mesmo tamanho, enquanto que a do terceiro é maior. Mancha ferruginea dorsal é percorrida em sua maior extensão por faixas castanho amareladas, ladeadas por tonalidade ferruginea (Fig. 7). As projeções tegumentares sempre no sexto ânulo e precedidas ou não por mancha branca, marginadas por pigmentação ferruginea. Apresenta, ainda, mancha branco-leitosa nos locais de inserção da cerda filiforme após os espiráculos, sendo referida por CASAgRANDE (1979) do terceiro ao sétimo segmentos abdominais para Caligo beltrao.
Projeções da placa suranal de coloração creme com ápice preto e inúmeras cerdas escuras, na região ventral de coloração ferruginea (Fig. 8).

Largura da cápsula cefálica variou entre 1,8-2,4 mm. As larvas atingem comprimento de $32 \mathrm{~mm}$, incluindo as projeções da placa suranal.

\section{LARVA DE TERCEIRO INSTAR \\ Cabeça (Fig. 14)}

Escolos dorsais perdem a cor castanho escura do ápice, passando a castanho claro. A faixa que surgiu no segundo instar aumenta em comprimento, alcançando o fronto-clípeo, formando assim duas faixas dorso-ventrais, castanho escuras, sendo uma delas estreita, proximal à sutura epicranial, contorna o frontoclípeo e ladeada por mancha de cor branco-amarelada que desce do escolo dorsal. Lateral a esta, uma segunda faixa, castanho escuro mais larga que chega aos estemas (Fig. 14).

\section{Tórax e abdome (Figs 15-16)}

Tegumento de coloração verde intenso, manchas anteriormente verde-claras, agora branco-leitosas encimadas por cerdas. Faixa branca supraespiracular, ladeada por tonalidade vermelho-carmin. Áreas espiracular e subespiracular vermelhocarmin com manchas branco-leitosas encimadas por cerdas, área ventral de coloração vermelho-carmin. A mancha dorsal é maior, amarelo-pálido é antecedida e precedida por manchas brancas. Pontuação ferruginea no primeiro segmento abdominal (Fig. 15).

Projeções da placa suranal ventralmente avermelhada e com inúmeras manchas brancas leitosas encimadas por cerdas claras e escuras (Fig. 16).

Largura da cápsula cefálica variou entre 2,6-3,1 mm. As larvas podem atingir $46 \mathrm{~mm}$ de comprimento, incluindo as projeções da placa suranal.

\section{LARVA DE QUARTO INSTAR \\ Cabeça (Fig. 17)}

Escolos dorsais, do ápice em direção à base brancos pouco amarelados, e castanhos posteriormente até a metade basal aproximadamente. Na faixa escura mais larga uma mancha de cor creme. Lateralmente, com pontuações castanhas dispersas. As faixas originadas dos escolos dorsais no segundo instar, aumentam em comprimento, contornando o fronto-clípeo (Fig. 17).

\section{Tórax e abdome (Figs 18-19)}

Tegumento de coloração verde. Faixa supraespiracular branca com manchas vermelho carmin aumenta em largura, ultrapassando os espiráculos. Mancha maior dorsal amarelopálido é contornada por coloração castanho escuro, quase preto, mostrando projeções tegumentares da mesma cor (Fig. 18).

Projeções da placa suranal apresentam manchas brancoleitosas encimadas por cerdas (Fig. 19).

Largura da cápsula cefálica variou entre 4,2-4,7 mm. As larvas podem alcançar o comprimento de $69 \mathrm{~mm}$, incluindo as projeções da placa suranal. 

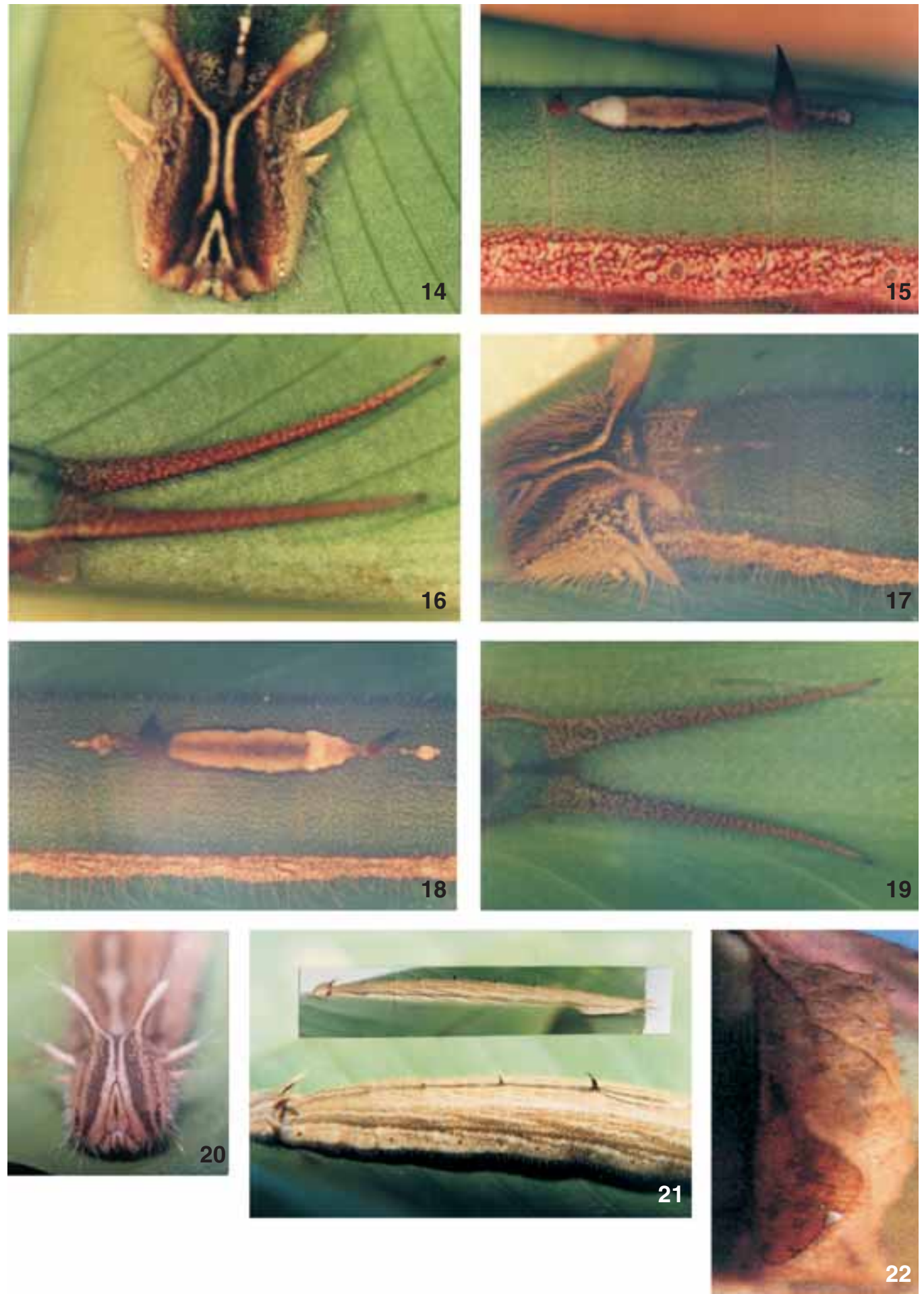

Figuras 14-22. Caligo teucer. (14-16) Larva de terceiro estádio: (14) vista frontal da cabeça; (15) laterais do terceiro e quarto segmentos abdominais; (16) projeções da placa suranal; (17-18) larva de quarto estádio: (17) vista dorsal da cabeça e tórax; (18) vista dorsal do terceiro e quarto segmento abdominal; (19) projeções da placa suranal; (20-21) larva de quinto estádio: (20) cabeça; (21) tórax e abdome; (22) pupa, vista lateral.

Revista Brasileira de Zoologia 23 (4): 1243-1250, dezembro 2006 
LARVA DE QUINTO INSTAR

\section{Cabeça (Fig. 20)}

Coloração geral bege com pontos e faixas castanho-escuro e com cerdas bege. Escolos dorsais, anteriormente totalmente bege. Mancha que surgiu no quarto instar da segunda faixa castanho escura aumenta, separando-a em duas faixas castanho-escuras. A faixa mais interna, castanho escura, circunda posteriormente os dois escolos dorsais, tornando-os castanho escuros em suas metades basais, seguida por faixa bege que desce do escolo dorsal. Lateral a esta, uma segunda faixa castanho escura, mais larga origina da base dos escolos dorsais. Lateralmente, observa-se outra faixa bege, finalmente uma terceira, castanho-escura, que atinge os estemas, contornando-os. Mancha do fronto-clípeo torna-se alongada, não mais de forma losangular (Fig. 20).

Tórax e abdome (Fig. 21)

Corpo pubescente de coloração geral castanho com faixas e estrias de coloração castanho escuras e pretas. No tórax, faixa dorsal de coloração bege contornada por duas linhas pretas, que se unem nos segmentos abdominais, continua pela área dorsal etermina entrea base das projeções da placa suranal. A faixa e projeções dorsais são similares àquelas apresentadas pelas larvas de quinto instar de Caligo illioneus illioneus (Cramer, 1775) (CLEARE 1926) e Caligo martia (Godart, [1824]) (CASAGRANDE $\&$ MIELKE 2000a).

$\mathrm{Na}$ área dorsal dos segmentos abdominais com cinco a seis projeções tegumentares pretas, sendo a do terceiro segmento maior que as demais (Fig. 21). Estas mesmas estruturas são observadas em C. illioneus illioneus

(Cleare 1926), C. beltrao (CAsagrande 1979), C. eurilochus (Malo \& Willis 1961) e C. martia (CAsagrande \& Mielke 2000a).

Área supraespiracular pouco mais escura que o restante do corpo, marcada tanto dorsal como ventralmente por faixas mais claras. Área espiracular com a mesma coloração do restante do tegumento. Área ventral castanha com pontos escuros.

Pernas torácicas castanho-avermelhadas, e falsas pernas com a mesma coloração da área ventral, com planta apresentando ganchos distribuídos em mesal penelipse, triordinal e unisserial, iguais aos descritos por CASAGRANDE (1979) para C. beltrao e por CASAGRANDE \& Mielke (2000a) para C. martia. Projeções da placa suranal dorsal mente castan has e com várias cerdas e inúmeros pontos pretos, e ventralmente escura quase preta.

Largura da cápsula cefálica variou entre 6,6-7,4 mm. As larvas podem alcançar o comprimento de $125 \mathrm{~mm}$, incluindo as projeções da placa suranal.

PupA (Fig. 22)

Tipo obtecta, apresenta coloração geral variável, amarelada a amarelo-pardo, com faixas e estrias verde-musgo e preto. Com estreita faixa de coloração castanha na parte dorsal, desde o vértice até o cremaster. Esta faixa também foi observada em Caligo memmon (C. Felder \& R. Felder, 1867) eCaligo atreus (Kollar,
1850) por Young \& MuYSHONDT (1985), e em C. martia por Casagrande \& Mielke (2000a) e C. beltrao por Casagrande (1979).

Várias cerdas estão distribuídas por todo o corpo na linha média dorsal, no vértice e próximo aos olhos, também presentes em C. eurilochus (MALO \& WILLIS 1961) e C. martia (Casagrande \& Mielke 2000a).

Lateralmente, próximo ao meio das tecas alares, duas manchas prateadas contornadas em preto, sendo uma de forma triangular maior, e outra circular e menor, diferente das encontradas por CASAGRANDE (1979) em C. beltrao e em C. martia por Casagrande \& Mielke (2000a).

Abdome com linhas oblíquas de cor escura, desde a linha média até as laterais sobre os espiráculos, como àquelas citadas por Young \& MUYSHONDT (1985) para C. atreus e C. memmon, e para C. martia por CASAgrande \& Mielke (2000a) e também em Dasyophtalma rusina rusina (Godart) por CASAGRANDE $\&$ MIELKE (2000b).

Comprimento das pupas pode variar entre $39-42 \mathrm{~mm}$, e a largura máxima, na base das tecas alares entre $21-24 \mathrm{~mm}$.

\section{AGRADECIMENTOS}

À CAPES pela concessão de bolsa ao primeiro autor, possibilitando a realização deste trabal ho e ao CNPq pela bolsa à M.M. Casagrande.

\section{REFERÊNCIAS BIBLIOGRÁFICAS}

Antunes, F.F.; A.O. Menezes Jr; M Tavares \& G.R.P. Moreira. 2003. Ultraestrutura tegumentar externa dos estágios imaturos de Heliconíneos neotropicais. I. Eueides isabella dianasa (Hübner, 1906). Revista Brasileira de Entomologia, Curitiba, 46 (4): 603-610.

BLAndin, P. \& H. Descimon. 1975. Contribution a la connaissance des lépidoptères del'Équateur les Brassolinae (Nymphalidae). Annales dela Sociétéentomologique de France, N.S., Paris, 11 (1): 3-28.

BouRgogne, J. 1951. Ordre des Lépidoptères, p. 174-448. In: P.P. GrASSÉ. (Ed.). Traité de zoologie, anatomie, systématique, biologie. 10. Paris, Masson.

BRown JR, K.S. \& A.V.L.FREITAS. 1999. Lepidoptera, p. 225-243. In: C.R.F. Brandão \& E.M. Cancello (Eds). Biodiversidade do Estado de São Paulo, Brasil: síntese do conhecimento ao final do século XX. Invertebrados terrestres. 5. São Paulo, FAPESP, 279p.

Casagrande. M.M. 2002. Naropini Stichel, taxonomia e imaturos (Lepidoptera, Nymphalidae, Brassolinae). Revista Brasileira de Zoologia, Curitiba, 19 (2): 467-569.

CASAGRANDE. M.M. 1979. Sobre Caligo beltrao (Illiger). I. Taxonomia, biologia, morfologia das fases imaturas e distribuições espacial e temporal (Lepidoptera, Satyridae, Brassolinae). Revista Brasileira de Biologia, Rio de Janeiro, 39 (1): 173-193.

CASAgRande. M.M. \& O.H.H. Mielke. 2000a. Larva de quinto estádio e pupa de Caligo martia (Godart). (Lepidoptera, Nymphalidae, Brassolinae). Revista Brasileira de Zoologia, 
Curitiba, 17 (1): 65-74

Casagrande. M.M. \& O.H.H. Mielke. 2000b.Larva de quinto estádio e pupa de Dasyophtalma rusina rusina (Godart). (Lepidoptera, Nymphalidae, Brassolinae). Revista Brasileira de Zoologia, Curitiba, 17 (2): 401-404.

CleARE, L.D. 1926. On thelife-history of Caligo illioneus illioneus, Cram. (Lep., Morphidae). Transactions of the Entomological Society of London, London, 76: 361-366.

FreitAs, A.V.L. \& P.S. Oliveira. 1992. Biology and behavior of the neotropical butterfly Eunica bechina (Nymphalidae) with special reference to larval defence against ant predation. Journal of Research on the Lepidoptera, Beverly Hills, 31 (1-2): 1-11.

Gallo, D.; O. Nakano; S. Silveria Neto; R.P.L. Carvalho; G.C. Baptista; E. Berti Filho; J.P.P. Parra; R.A. Zuchi; S.B. Alves; J.D. Vendramim; L.C. Marchini; J.R.S. Lopes; C. Оmoto. 2002. Entomologia agrícola. Piracicaba, Esalq, 920p.

García-BARRos, E. 1987. Morfology and chaetotaxy of the first instar larvae of six species of the Satyrus (s. I.) series (Lepidoptera, Nymphalidae). Systematic Entomology, London, 12: 335-344.

GarcíA-BARRos, E. 1989. Morfologia larvaria de Hipparchia fidia (L. 1767) (Lepidoptera, Nymphalidae). Nouvelle Revue de Entomologie, N.S., Paris, 6: 71-83.

García-Barros, E. 1999. Filogenia y Evolucíon de Lepidoptera. Boletín Sociedad Entomológica Aragonesa, Zaragoza, 26: 475-483.

García-Barros, E. \& J.M. Martín. 1991. Immature stages of Hipparchia Fabricius and the systmatics of the 'Satyrus series' (Lepidoptera, Nymphalidae, Satyrinae). Systematic Entomology, Londres, 16: 407-426.

HARVEY, D.J. 1991. Higher classification of the Nymphalidae,
Appendix B, p. 255-273. In: H.F. Nıннот (Ed.). The development and evolution of butterfly wing patterns. Washington, Smithsonian Institution Press, 297p.

Hinton, H.E. 1946. On the morphology and nomenclature of setae of the Lepidopterous Larvae, with notes on the phylogeny of the Lepidoptera. Transactions of the Royal Entomological Society London, Londres, 97: 1-35.

MALO, F. \& E.R. WilLis. 1961. Life history and biological control of Caligo eurilochus, a pest of banana. Journal of Economic Entomology, Menasha, 54 (3): 530-536.

Peterson, A. 1962. Larvae of insects. An introduction to Neartic species. Part II: Lepidoptera and plant infesting Hymenoptera. Ann Arbor, Edwards Brothers, 315p.

Penz, C.M.; A. Aiello \& R.B. SRygley. 1999. Early stages of Caligo illioneus and Caligo idomeneus (Nymphalidae, Brassolinae) from Panama, with remarks on larval food plants for the subfamily. Journal of the Lepidopterist's Society, Lawrence, 53 (4):142-152.

Ramos, F.A. 2000. Nymphalid butterfly communities in an amazonian forest fragment. Journal of Research on the Lepidoptera, Beverly Hills, 35: 29-41.

Silva, A.G.G.; C.R. GonçAlves; D.M. Galvão; A.J.L. Gonçalves; J. Gomes; M.N. Silva \& L. Simonı. 1968. Quarto catálogo dos insetos que vivem nas plantas do Brasil, seus parasitos e predadores. Rio de Janeiro, Laboratório de Patologia Vegetal, Tomo 1, $2^{\mathrm{a}}$ Parte, XXVI+622p.

Stehr, F.W. 1987 Order Lepidoptera, p. 288-304. In: F.W. Stehr (Ed.). Immature Insects. Duboque, Kendall Hunt, 754p.

Young, A. \& A. MuYshondt. 1985. Notes on Caligo memmon Felder and Caligo atreus Kollar (Lepidoptera: Nymphalidae: Brassolinae) in Costa Rica and El Salvador. Journal of Research on the Lepidoptera, Beverly Hills, 24: 154-175.

Recebido em 27.XI.2005; aceito em 22.XI.2006S.

Revista Brasileira de Zoologia 23 (4): 1243-1250, dezembro 2006 